\title{
УДК:632.44:631.53.02 https://doi.org/10.53040/gppb7.2021.10 \\ ИДЕНТИФИКАЦИЯ FUSARIUM SPP. И ALTERNARIA SPP. В СЕМЕНАХ НЕКОТОРЫХ ОВОЩНЫХ КУЛЬТУР
}

\author{
Дягилева А.В., Туманова Л.Г., Митин В.А., Грэждиеру К.Б. \\ Институт генетики, физиологии и защиты растений, Кишинэу, Республика Молдова \\ e-mail:angela.deaghileva@igfpp.md
}

\begin{abstract}
In this paper the results of molecular diagnostics of Fusarium spp. and Alternaria spp. in bell pepper and eggplant seeds of local genotypes at different time points of storage are presented. The diagnostics was effectuated using nested-PCR protocol with genus-specific and species-specific primers to $F$. $o x$ ysporum, $F$. solani, $F$. nivale, $F$. equiseti, $F$. culmorum, $F$. verticillioides, $F$. avenaceum, $A$. alternata, and $A$. solani. In the samples of studied bell pepper and eggplant genotypes A. alternata was found. In eggplant seeds certain species of Fusarium spp. were identified.
\end{abstract}

Key words: PCR, Solanum melongena, Capsicum annuum, Fusarium, Alternaria.

\section{Введение}

Fusarium и Alternaria - два крупных рода почвенных микромицетов тесно взаимодействующих с растениями. Большинство их видов вызывают болезни различных сельскохозяйственных культур, которые приводят к значительным потерям урожая и к катастрофическому ухудшению его качества [1]. В течении вегетационного периода патогены данных родов обнаруживаются во всех органах зараженных растений $[2,3]$. Показано, что они системно передаются через инфицированные материнские растения в семена, достигая зародыша [4].

В последние годы семена стали международным товаром, используемым для обмена гермоплазмой по всему миру. Возникает опасность занесения патогенов растений на новые территории. Патогенная микрофлора, переносимая семенами, является причиной их гниения и некроза, снижение или полное подавление всхожести, гибели проростков, развитие системных болезней растений, как следствие - сокращение посевов и урожайности культур. Продукция из таких семян непригодна для употребления из-за снижения питательной ценности и часто за счет содержания микотоксинов опасных для здоровья человека и животных [5]. Таким образом, семена могут быть источником фитосанитарного риска при их импорте и использовании в сельскохозяйственных целях, так как высока вероятность акклиматизации и распространения, связанных с семенами карантинных организмов [6].

Установлено, что патогены родов Fusarium и Alternaria вызывают максимальные потери урожая перца сладкого (Capsicum annuит) и баклажана (Solanum melongena), вызывая различные виды сосудистых заболеваний и гнили [7-9].

Цель данной работы - ПЦР-идентификация грибков родов Fusarium и Alternaria в семенах перца сладкого (Capsicum annuит) и баклажана (Solanum melongena) различных сроков хранения селекции ИГФЗР. Молекулярный анализ проведен посредством двухстадийной и мультиплекс ПЦР и набора праймеров, разработанных для общих и видоспецифичных областей геномов вышеупомянутых патогенов.

\section{Материалы и методы}

В исследовании были использованы семена нескольких сортов перца сладкого ('Fildeş', 'Caolin', 'Excelent') и баклажана ('Vănatic', 'Rada', 'Laura', 'Magda') различных сроков хранения. Выделение суммарной ДНК проводили СТАВ-методом из 150-200 мг растительного материала [10]. Для идентификации Fusarium spp. и Alternaria spp. был осуществлен дизайн собственных праймеров как описано ранее [2].

ПЦР проводилась в $25 \mu \mathrm{l}$ реакционной смеси, содержащей $66 \mathrm{mM}$ трис-HCl (pH-8.4), $16 \mathrm{mM}$ $\left(\mathrm{NH}_{4}\right)_{2} \mathrm{SO}_{4}, 2 \mathrm{mM} \mathrm{MgCl}, 0.1 \%$ Tween 20, 7\% глицерина, $100 \mathrm{mkg} / \mathrm{ml}$ BSA (Bovin Serum Albumin), по 0.2mM каждого из dNTP, по 5 рМ праймера и 0,2 единицы Tаq-полимеразы (Thermo Fisher 
Scientific), 10 нг ДНК. В качестве молекулярного маркера использовался $100 \mathrm{~kb}$ DNA ladder (Thermo Fisher Scientific).

Первый раунд двухстадийной ПЦР включал: 1 цикл при $95^{\circ} \mathrm{C}$ (денатурация) в течение 3 мин, $60^{\circ} \mathrm{C}$ (отжиг) - 1 мин, $72^{\circ} \mathrm{C}$ (элонгация) - 1 мин, затем 29 циклов: $95^{\circ} \mathrm{C}-1$ мин, $60^{\circ} \mathrm{C}-1$ мин, $72^{\circ} \mathrm{C}$ 1 мин. Условия второго раунда: $95^{\circ} \mathrm{C}-1$ мин, $60^{\circ} \mathrm{C}-1$ мин, $72^{\circ} \mathrm{C}-1$ мин (30 циклов).

Продукты амплификации разделяли в 1,5\% агарозном геле при 6 B/см в ТВЕ буфере (pH $8.0)$ с бромидом этидия, визуализировали в УФ (302 нм) и фотографировали.

\section{Результаты и обсуждение}

Для выявления потенциальной фузариозной и/или альтернариозной инфекции в исследуемом материале в двухстадийной ПЦР были использованы праймеры созданные на основе неспецифичных участков последовательностей геномов Fusarium spp. и Alternaria spp. Результат молекулярного анализа показал присутствие ДНК Alternaria spp. во всех генотипах баклажана и перца, за исключением одного образца 'Fildeş' (Capsicum annuum, 2011). Патогены рода Fusarium были обнаружены только в семенах баклажана. Суммарно результаты молекулярного анализа ДНК семян перца и баклажана с использованием праймеров для выявления Fusarium spp., Alternaria spp., а также видов A. alternata и A. solani представлены в таблице 1.

Таблица 1. Fusarium spp. и Alternaria spp. в семенах перца сладкого и баклажана различных сроков хранения

\begin{tabular}{|c|c|c|c|c|c|c|c|c|c|c|c|c|c|c|c|}
\hline \multirow{3}{*}{$\underset{\text { Патоген }}{\text { Генотиі }}$} & \multicolumn{9}{|c|}{ Перец сладкий } & \multicolumn{6}{|c|}{ Баклажан } \\
\hline & \multicolumn{3}{|c|}{2011} & \multicolumn{3}{|c|}{2015} & \multicolumn{3}{|c|}{2020} & \multicolumn{4}{|c|}{2011} & \multicolumn{2}{|c|}{2018} \\
\hline & $\mathrm{F}$ & C & $E$ & $\mathrm{~F}$ & C & E & $\mathrm{F}$ & C & E & $\mathrm{V}$ & $R$ & $\mathrm{~L}$ & $M$ & $R$ & $M$ \\
\hline Fusarium spp. & - & - & - & - & - & & - & - & & + & - & + & + & - & + \\
\hline Alternaria spp. & - & + & + & + & + & $\boldsymbol{+}$ & + & + & $\boldsymbol{t}$ & + & + & + & + & + & + \\
\hline A. alternata & - & + & + & + & + & + & + & + & + & + & + & + & + & + & + \\
\hline A. solani & - & - & - & - & - & - & - & - & - & - & - & - & - & - & - \\
\hline
\end{tabular}

F - 'Fildeş', C - 'Caolin', E - 'Excelent', V - 'Vănatic', R - 'Rada', L - 'Laura', M - 'Magda'.

Fusarium spp. идентифицирован у сортов баклажана: 'Vănatic', 'Laura', 'Magda' - урожая 2011 года, 'Magda' - 2018. Alternaria spp. выявлена во всех генотипах перца и баклажана, за исключением сорта 'Fildeş' (Capsicum anпиит, 2011). В семенном материале различных сроков хранения была обнаружена A. alternata. A. solani в исследованных образцах отсутствует. Примеры синтеза фрагментов, демонстрирующих присутствие патогенной ДНК в растительном материале, показаны на рисунке 1.
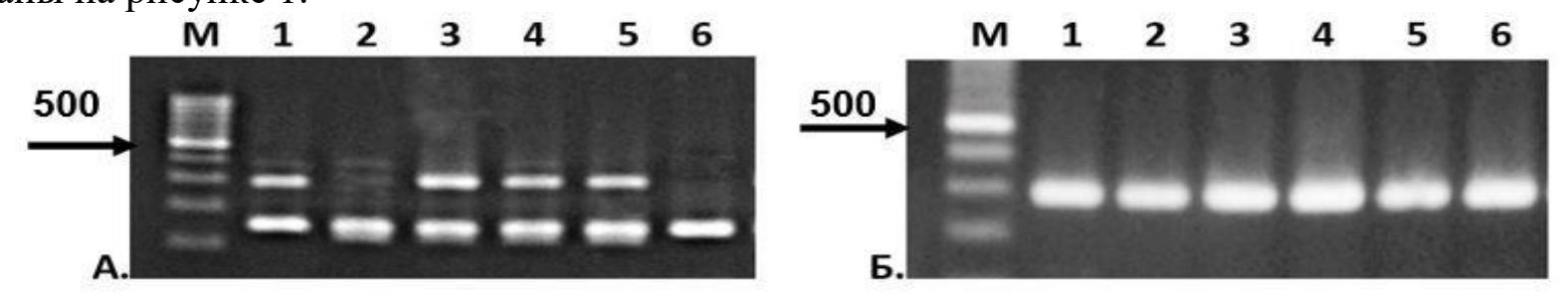

Рисунок 1. Электрофореграмма продуктов ПЦР при использовании праймеров для обнаружения Fusarium spp., Alternaria spp. (А) и A. alternata (Б) в ДНК семян баклажана. А, Б: 1, 5. 'Magda'; 2,6. 'Rada'; 3. 'Vănatic'; 4. 'Laura'

В результате проведения мультиплекс-ПЦР (рис.1А.) фрагмент длиной 150 п.о. означает наличие патогенов рода Alternaria во всех исследованных генотипах баклажана. Фрагмент длиной 300 п.о. показывает присутствие ДНК Fusarium spp. в семенах сорта 'Magda' как 2011 г (А.1), так и 2018 г (A.5), а также в семенах сортов 'Vănatic' (A.3) и 'Laura' (A.4). В семенах сорта 'Rada' данный фрагмент отсутствует. Как результат двухстадийной ПЦР (рис.1Б.) синтезировался фрагмент длиной 289 п.о. во всех образцах при использовании праймеров для обнаружения A. alternata. 
Далее была проведена молекулярная идентификация различных видов Fusarium с использованием специфических праймеров для выявления $F$. solani, F. avenaceum, F. verticillioides, $F$. oxysporum, F. nivale, F. culmorum, F. equiseti. Результаты ПЦР-анализа ДНК семян баклажана по выявлению видового состава грибков рода Fusarium представлены в таблице:

Таблица 2. Идентификация видов Fusarium spp. в семенах Solanum melongena различных сроков

\begin{tabular}{|c|l|c|c|c|c|c|c|c|}
\hline $\begin{array}{l}\text { Год закладки } \\
\text { на хранение }\end{array}$ & Генотипы & Fo & Fv & Fa & Fn & Fc & Fe & Fs \\
\hline \multirow{3}{*}{2011} & Vănatic & - & + & - & - & - & - & - \\
\cline { 2 - 9 } & Rada & - & - & - & - & - & - & - \\
\cline { 2 - 9 } & Laura & - & + & - & - & - & - & - \\
\cline { 2 - 9 } & Magda & - & + & + & - & - & - & - \\
\hline \multirow{3}{*}{2018} & Rada & - & - & - & - & - & - & - \\
\cline { 2 - 9 } & Magda & - & + & - & - & - & + & - \\
\hline
\end{tabular}

Fo - F. oxysporum, $\mathrm{Fv}-F$. verticillioides, $\mathrm{Fa}-F$. avenaceum, $\mathrm{Fn}-F$. nivale,

Fc - F. culmorum, Fe - F. equiseti, Fs - F. solani.

В большинстве изученных сортов баклажана обнаружен $F$. verticillioides: 'Vănatic', 'Laura', 'Magda' - урожая 2011 года, 'Magda' - 2018. В единичных случаях в семенах сорта 'Magda' выявлен $F$. avenaceum (урожай 2011 года) и $F$. equiseti (урожай 2018 года).

Результат двухстадийной ПЦР, демонстрирующий присутствие патогенов $F$. verticillioides, $F$. avenaceum и $F$. equiseti в исследованных образцах ДНК баклажана, выборочно показан на рисунках 2 и 3.

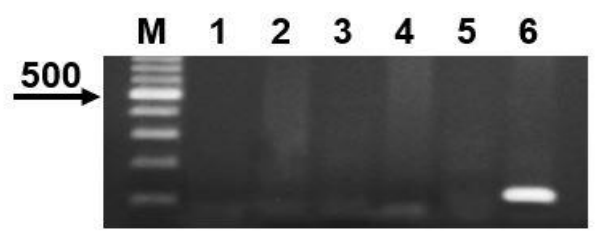

Рисунок 2. Электрофореграмма ПЦР-продуктов с использованием праймеров для выявления $F$. equiseti в генотипах баклажана.

1, 5. 'Rada', 2, 6. 'Magda', 3. 'Vănatic', 4. 'Laura'.

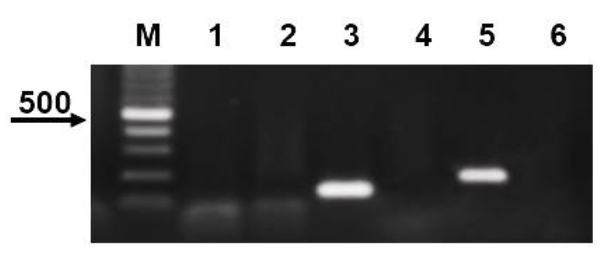

Рисунок 3. Электрофореграмма ПЦР-продуктов с использованием праймеров для выявления видов фузариума в ДНК семян сорта 'Magda'.

1. F. solani, 2. F. nivale, 3. F. avenaceum, 4. F. culmorum, 5. F. verticillioides, 6. F. oxysporum.

Ампликон размером 104 п.о., полученный в результате действия специфических праймеров к F. equiseti, выявлен только у сорта 'Magda' (рис. 2.6). В результате проведения двухстадийной ПЦР с использованием праймеров для выявления $F$. avenaceum во втором раунде синтезируется фрагмент длиной 140 п.о. Пример синтеза данного фрагмента на ДНК сорта 'Magda' показан на рисунке 3.3. Здесь же, ампликон размером 160 п.о. указывает на присутствие в семенном материале данного сорта F. verticillioides (рис. 3.5).

\section{Выводы}

Проведена молекулярная идентификация Fusarium spp. и Alternaria spp. в семенах перца сладкого и баклажана различных сроков хранения. Alternaria spp. выявлена во всех генотипах перца и баклажана, за исключением сорта 'Fildeş' (Capsicum annuum, 2011). В семенном материале различных сроков хранения была обнаружена A. alternata. A. solani в исследованных образцах отсутствует. Fusarium spp. обнаружен только в семенах баклажана: 'Vănatic', 'Laura', 'Magda' урожая 2011 года, 'Magda' - 2018. В семенах сорта 'Magda' разных сроков хранения обнаружены патогенов $F$. verticillioides, $F$. avenaceum и $F$. equiseti, в семенах 'Vănatic' и 'Laura' урожая 2011 года - F. verticillioides. В семенах сорта 'Rada' патогены рода Fusarium отсутствуют. 
Исследования проведены в рамках проекта Государственной Программы 20.80009.5107.11 «Длительное сохранение генетических ресурсов растений в генном банке с использованием методов молекулярной биологии в тестировании состояния здоровья растительной зародышевой плазмы», финансируемой Национальным Агентством по Исследованиям и Развитию Республики Молдовы.

\section{Литература}

1. СОКОЛОВА, Л.М., БУХАРОВ, А.Ф., ИВАНОВА, М.И. Применение последовательных отборов при селекции моркови столовой на устойчивость к Fusarium sp. и Alternaria sp. B: Аграрная наука, 2020, том 339, № 6, c. 78-83.

2. DEAGHILEVA, A., MITIN, V., GRAJDIERU, C., TUMANOVA, L. Monitoring of Alternaria spp. and Fusarium spp. mixed infections in symptomless tomato plants, using molecular methods of plant pathogen identification. В: Инновационные аспекты улучшения сельскохозяйственных культур Интернациональная научно-практическая конференция, Paşcani, IFP, 2018, с. 425-428.

3. DEAGHILEVA, A.D., MITIN, V.A., GRAJDIERU, C.B., TUMANOVA, L.G. Molecular identification of Fusarium species in tomato. B: Тенденции развития агрофизики: от актуальных проблем земледелия $и$ растениеводства к технологиям будущего материалах Международная научная конференция, СанктПетербург, АФИ, 2017, с. 451-454.

4. NALLATHAMBI, P., UMAMAHESWARI, C., SANDEEP, K. Lal et al. Mechanism of Seed Transmission and Seed Infection in Major Agricultural Crops in India. In book: Seed-Borne Diseases of Agricultural Crops: Detection, Diagnosis \& Management. 2020, p. 749-791.

5. AMZA, J. Seed Borne Fungi; Food Spoilage, Negative Impact and Their Management: A Review. In: J. Food Science and Quality Management. 2018, vol. 81, p. 70-79.

6. Международные стандарты по фитосанитарным мерам № 38 (МСФМ). Международное перемещение семян, 2018, https://snund.am/wp-content/uploads/2018/10/ISPM_38.pdf.

7. CRUZ-CABRAL, L., TERMINIELLO, L., FERNÁNDEZ-PINTO, V. et al. Natural occurrence of mycotoxins and toxigenic capacity of Alternaria strains from moldy peppers. In: Int. J. Food Microbiol., 2016, v. 236, p. 155-160.

8. PAWAR, S., KHAIRE, P., MANE, S. Management Strategies Used against Fungal Diseases of Capsicum. In: J. AgriCos e-Newsletter, 2020, v. 1, issue 5, № 8, p. 22-26.

9. HABIB, A., SHAHBAR, T.S., GHAZANFAR, M.U., ALI, S. et al. Location of Seed-borne Mycoflora of Eggplant (Solanum melongena) in different Seed Components and Impact on Seed Germinability. In: Int. J. of Agric. and Biol., 2007, v. 9. № 3, p. 514-516.

10. ISO 21571:2005(en) Foodstuffs - Methods of analysis for the detection of genetically modified organisms and derived products - Nucleic acid extraction [Online]. URL: https:// www.iso.org/obp/ui/\#iso:std:iso:21571:ed-1:v1:en 